\title{
РАСПРЕДЕЛЕНИЕ АКРИТАРХ В ПОГРАНИЧНЫХ СЛОЯХ КЕМБРИЯ И ОРДОВИКА РАЗРЕЗА СУХКРУМЯГИ (СЕВЕРНАЯ ЭСТОНИЯ)
}

Разрез Сухкрумяги, расположенный в северо-восточной части Таллина, вскрывает пограничный интервал кембрия и ордовика, представленный юлгазеской свитой верхнего кембрия и каллавереской свитой нижнего ордовика. Биостратиграфические исследования пограничных слоев кембрия и ордовика в районе Балтийско-Ладожского глинта позволили установить соотношения конодонтовой зональности с этими свитами, в том числе и в рассматриваемом разрезе (Kaljo и др., 1986).

Пробы для изучения акритарх и конодонтов отбирались параллельно, что позволяет уверенно связать распределение акритарх с конодонтовой зональностью. Акритархи изучены Н. А. Волковой, геологическая характеристика разреза составлена К. А. Менс. Беззамковые брахиоподы определил И. В. Пуура (Ин-т геол. АН ЭССР), за что авторы искренне ему благодарны.
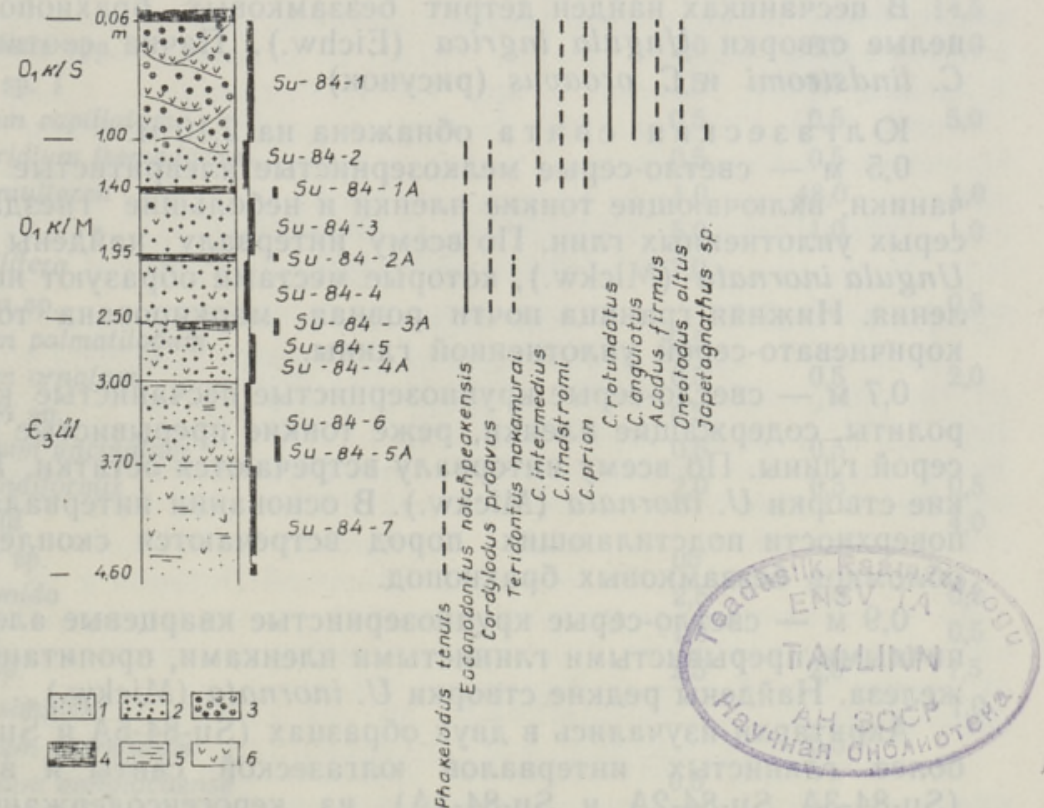

Пограничный интервал кембрия и ордовика разреза Сухкрумяги. Справа от литологической колонки показаны места опробования акритарх (Su-84-1A) и конодонтов (Su-84-1).

1 - крупнозернистый алевролит, 2 - мелкозернистый песчаник, 3 - среднезернистый песчаник, 4 - керогенсодержащий аргиллит, 5 - глина, 6 - створки беззамковых брахиопод и их детрит. 
Приведем опйсание опробованной части разреза Сухкрумяги (сверху вниз). Место взятия проб для изучения акритарх и конодонтов показано на рисунке. Распределение конодонтов на нем приведено согласно даниым В. Вийра (Kaljo и др., 1986).

Под темно-коричневыми горизонтально-слоистыми керогенсодержащими аргиллитами тюрисалуской свиты $\left(\mathrm{O}_{1} \mathrm{tr}\right)$ обнажается песчаная толща каллавереской свиты $\left(\mathrm{O}_{1} \mathrm{kl}\right)$, представленная суурйыгиской $\left(\mathrm{O}_{1} \mathrm{klS}\right)$ и маардуской $\left(\mathrm{O}_{1} \mathrm{kl} M\right)$ пачками.

Суурйыгиская пачка мощностью 1 м сложена желтоватосерыми мелко- и среднезернистыми кварцевыми песчаниками, содержащими детрит беззамковых брахиопод, часто ориентированный по косой слоистости. Песчаники слабо сцементированы, за исключением верхних 5-10 см, которые в виде линз сильно пиритизованы (т. н. пиритовый слой).

Косослоистые песчаники суурйыгиской пачки местами отделены от подстилающих горизонтальнослоистых песчаников маардуской пачки прерывистой глинистой пленкой. Граница между этими пачками, кроме текстур, проводится по изменению окраски и гранулометрического состава отложений.

По составу комплекса конодонтов (рисунок) отложения суурйыгиской пачки в разрезе Сухкрумяги относятся к зоне C. rotundatusC. angulatus. Из-за отсутствия глинистых пород в составе пачки, акритархи не изучены.

Ма ардуская пачка мощностью 1,5 м представлена светлосерыми мелкозернистыми слабосцементированными кварцевыми песчаниками с тонкими прерывистыми прослоями (до 2 см) темно-коричневого керогенсодержащего аргиллита на глубинах 1,$40 ; 1,95$ и 2,50 м от кровли свиты. Нижняя граница пачки слабоволнистая, литологически выражена нечетко.

В песчаниках найден детрит беззамковых брахиопод и единичные целые створки Ungula ingrica (Eichw.). Пачка соответствует зонам C. lindstromi и C. proavus (рисунок).

Юлгаз еск а с в и та обнажена на 2,10 м:

0,5 м - светло-серые мелкозернистые алевритистые кварцевые песчаники, включающие тонкие пленки и небольшие гнезда коричневатосерых уплотненных глин. По всему интервалу найдены целые створки Ungula inornata (Mickw.), которые местами образуют небольшие скопления. Нижняя граница почти ровная, маркирована тонким прослоем коричневато-серой уплотненной глины.

0,7 м - светло-серые крупнозернистые песчанистые кварцевые алевролиты, содержащие пленки, реже тонкие прерывистые прослои темносерой глины. По всему интервалу встречаются остатки Torellella и редкие створки $U$. inornata (Mickw.). В основании интервала, на волнистой поверхности подстилающих пород встречаются скопления створок и обломков беззамковых брахиопод.

0,9 м - светло-серые крупнозернистые кварцевые алевролиты с единичными прерывистыми глинистыми пленками, пропитанными окислами железа. Найдены редкие створки $U$. inornata (Mickw.).

Акритархи изучались в двух образцах (Su-84-5A и Su-84-4A) из наиболее глинистых интервалов юлгазеской свиты и в трех образцах (Su-84-3A, Su-84-2A и Su-84-1A) из керогенсодержащего аргиллита маардуской пачки. Во всех образцах встречались многочисленные акритархи хорошей сохранности. Обнаружены два комплекса акритарх: один в юлгазеской свите, другой в каллавереской. Видовой состав этих комплексов и количественное распределение видов в изученных образцах приведены в таблице. 


\begin{tabular}{c|c|c}
\hline Вид & $\begin{array}{c}\text { Юлгазеская } \\
\text { свита }\end{array}$ & $\begin{array}{c}\text { Маардуская } \\
\text { пачка }\end{array}$ \\
\cline { 2 - 3 } & Su-84-5A $\mid$ Su-84-4A & Su-84-3A $\mid$ Su-84-2A $\mid$ Su-84-1A \\
\hline
\end{tabular}

Cristallinium spp.

Cymatiogalea aff. bellicosa

C. aff. cuvillieri

C. aff. multarea

C. aff. velifera

Cymatiogalea spp.

Leiofusa stoumonensis

Leiofusa sp.

Leiosphaeridia spp.

Micrhystridium sp.

Stelliferidium aff. cortinulum

Stelliferidium sp.

Timofeevia lancarae

T. phosphoritica

Timofeevia sp.

Veryhachium dumontii

Vulcanisphaera turbata

Acanthodiacrodium angustum

A. comptulum

A. echinatum

A. polymorphum

A. striatum

Acanthodiacrodium spp.

Arbusculidium sp. I

Baltisphaeridium capillatum

Buedingisphaeridium tremadocum

Cymatiogalea multarea

C. cuvillieri

C. aff. columellifera

Cymatiosphaera sp.

Dasydiacrodium palmatilobum

Dasydiacrodium ornatum

Dasydiacrodium sp.

Goniosphaeridium uncinatum

Ladogella rotundiformis

Lunulidia lunula

Pterospermella sp.

Priscotheca tumida

Priscotheca sp.

Polygonium spp.

Stelliferidium simplex

Trachydiacrodium coarctatum

Trichosphaeridium annolovaense

T. hirtum

Vulcanisphaera sp.

«Петли Эйзенака»

2,5
0,5
10,5
0,5
7,5
1,5
1,0
1,0
0,5
42,5
1,0
1,5
9,0
3,5
0,5
16,5

2,5

3,0

0,5

10,5

0,5

7,5

1,5

1,0

1,0

0,5

42,5

1,0

1,5

9,0

3,5

0,5

6,5

0,5

20,5

2,5

2,5

1,0

1,0

34,5

1,0

1,0

7,0

5,0

0,5

15,0
2,5

1,0

0,5

4,5

$3,5 \quad 2,0 \quad 0,5$

$\begin{array}{lll}43,0 & 12,0 & 19,0\end{array}$

$\begin{array}{lll}11,0 & 1,5 & 1,5\end{array}$

$2,0 \quad 0,5 \quad 6,5$

$\begin{array}{lll}1,0 & 11,0 & 4,0\end{array}$

$\begin{array}{lll}4,5 & 11,0 & 20,0\end{array}$

$\begin{array}{lll}1,0 & 0,5 & 2,0\end{array}$

14,5

$\begin{array}{lll}2,0 & 3,0 & 1,0\end{array}$

$1,5 \quad 0,5$

$\begin{array}{lll}0,5 & 0,5 & 5,0\end{array}$

$\begin{array}{rrr}0,5 & 0,5 & \\ 1,0 & 48,0 & 1,0\end{array}$

$\begin{array}{lll}5,0 & 1,0 & 1,0\end{array}$

7,0

0,5

$\begin{array}{lll}0,5 & 0,5 & 2,0\end{array}$

0,5

$0,5 \quad 0,5$

$\begin{array}{lll}2,0 & 0,5 & 0,5\end{array}$

05

$\begin{array}{lll}2,5 & 1,0 & 0,5\end{array}$

$1,0 \quad 0,5$

$2,5 \quad 2,0 \quad 1,5$

0,5

$\begin{array}{ll}0,5 & \\ 0,5 & 0,5\end{array}$

0,5

Количество подсчитанных

экземпляров 
Комплекс акритарх юлгазеской свиты очень близок по составу к комплексу акритарх стратотипического разреза данной свиты (Волкова, 1982). Наиболее очевидным их отличием является возрастающая роль в типовом юлгазеском комплексе рода Impluviculus (=Aranidium), который в комплексе разреза Сухкрумяги не найден. На данной стадии микрофитологического изучения юлгазеской свиты трудно заключить, связано ли это с сезонными изменениями в составе фитопланктона, или с изучением проб из разных стратиграфических уровней свиты. В аналогичном комплексе этого уровня на Восточном Ньюфаундленде (микрофлора A3: Martin, Dean, 1981) указанный род также не наблюдается. Для юлгазеского комплекса характерно совместное присутствие представителей среднего кембрия Cristallinium, Timofeevia, Vulcanisphaera turbata Martin (=V. aff. capillata) и появление в этих отложениях впервые Cymatiogalea, Stelliferidium, Leiofusa stoumonensis Vang., Veryhachium dumontii Vang. Указанное сочетание таксонов свойственно на Восточно-Европейской платформе отложениям первой половины верхнего кембрия, т. е. зоне Olenus - нижней части зоны Parabolina spinulosa (Martin, Dean, 1981).

Систематический состав комплекса акритарх маардуской пачки более разнообразен, чем комплекс юлгазеской свиты (таблица). Большинство видов, появляющихся в изученном разрезе с основания каллавереской свиты, известны в других разрезах на Восточно-Европейской платформе из отложений второй половины верхнего кембрия (Волкова, Голуб, 1985). Однако заметное участие в комплексе принимают также виды, найденные пока только в тремадокских отложениях: Acanthodiacrodium angustum (Downie) Combaz, A. comptulum Rasul, Dasydiacrodium ornatum Combaz, Priscotheca tumida Deunff и Lunulidia lunula (Eis.) Eis. Из них наиболее широко распространен A. angustum, который обнаружен в тремадоке Западной Европы, Восточного Ньюфаундленда, Северной Африки и на севере Аргентины (Martin, 1982). Другие таксоны имеют более ограниченное распространение. Так, A. comptulum известен из тремадока Англии (Rasul, 1979), D. ornatum - Северной Африки (Combaz, 1967; Jardiné и др., 1974), P. tumida-Северной Африки (Deunff, 1961; Combaz, 1967; Jardiné и др., 1974) и Англии (Rasul, 1979). Появление вышеотмеченных четырех видов в разрезе Сухкрумяги приурочено к подошве зоны C. proavus (проба Su-84-3A) и их распространение продолжается по всей маардуской пачке (пробы Su-84-2A и Su-84-1А). Наличие этих форм в составе комплекса акритарх свидетельствует, скорее всего, о тремадокском возрасте вмещающих отложений.

Последний из вышеперечисленных видов, Lunulidia lunula, описан из диктионемовых сланцев Ленинградской области (Eisenack, 1951, 1958). В разрезе Сухкрумяги этот вид, как и A. echinatum (Naum.) Volk. и A. striatum (Naum.) Volk., найдены только в самом верхнем образце, взятым из прослоя аргиллита, который подстилает непосредственно пссчаники, содержащие Cordylodus intermedius, C. lindstromi и C. prion (рисунок). Поскольку в Северной Эстонии с прослоев аргиллита часто начинается разрез тремадока (напр., в основании каллавереской свиты к западу от Таллина), то не исключено, что данный прослой относится уже к зоне C. lindstromi. Однако данных для такого вывода пока недостаточно.

В итоге следует отметить, что наблюдаемая четкая смена в вертикальном распределении комплексов акритарх обусловлена, прежде всего, стратиграфическим пробелом между юлгазеской и каллавереской свитами. Однако сказанное никоим образом не принижает стратиграфической ценности акритарх при расчленении отложений морских терригенных формаций и, судя по таксономическому составу этих комплексов, они могут служить целям межрегиональной корреляции. 
Волкова Н. А. О возрасте юлгазеской пачки на границе кембрия и ордовика в Эстонни. - Сов. геол., 1982, № 9, 85-88.

Волкова Н. А., Голуб Н. Н. Новые акритархы верхнего кембрия Ленинградской области (ладожская свита). - Палеонт. Ж., 1985, № 4, 90-98.

Combaz, A. Un microbios du Trémadocien dans un sondage d'Hassi-Messaoud. - Act. Soc. linn Bordeaux, 1967, 104E, N 29, 1-26.

Deunff, I. Un micrcplancton à Hystrichosphères dans le Tremadoc du Sahara. - Revue Micropaléont., 1961, 4, N 1, 37-52.

Eiscnack, A. Ober Hystrichosphaerideen und andere Kleinformen aus Baltischen Silur und Kambrium. - Senck, leth., 1951, 32, N1/4, 187-204.

Eisenack, A. Mikrofossilien aus dem Ordovizium des Baltikums. I. - Senck. leth., 1958, 39 , N $5-6,389-405$.

Jardiné, S., Combaz, A., Magloire, L., Peniguel, G., Vachey, G. Distribution stratigraphique des Acritarches dans le Paléozoique du Sahara a!gérien. - Rev. Palaeobot. Palynol., 1974, 18, N 1-2, 99-130.

Kaljo, D., Borovko, N., Heinsalu, H., Khazanovich, K., Mens, K., Popov, L., Sergeyeva, S., Sobolevskaya, R., Viira, V. The Cambrian-Ordovician boundary in the BalticLadoga clint area (North Estonia and Leningrad Region, USSR). - Proc. Acad. Sci. ESSR. Geol., 1986, 35, N 3, 97-108.

Martin, F. Some aspects of Late Cambrian and Early Ordovician acritarchs. - In: Bassett. M. G., Dean, W. T. (eds). The Cambrian-Ordovician Boundary: Sections, Fossil Distributions and Correlations. Nat. Mus. Wales, Geol. Ser. Cardiff, 1982, N 3, 29-40.

Martin, F., Dean, W. T. Middle and Upper Cambrian and Lower Ordovician acritarchs from Random Island, eastern Newfoundland. - Bull. Geol. Surv. Can., 1981, N 343 .

Rasul, S. M. Acritarch zonation of the Tremadoc Sories of the Shineton Shales, Wrekin, Shropshire, England. - Palynology, 1979, 3, 53-72. Геологический институт
Академии наук СССР

Поступила в редакцию 6/IV 1987

Институт геологии

Академии наук Эстонской ССР

\section{N. VOLKOVA, Kaisa MENS}

\section{AKRITARHIDE LEVIK KAMBRIUMI JA ORDOVIITSIUMI PIIRIKIHTIDES SUHKRUMÄE LÄBILOIKES (PÖJA-EESTI)}

On antud ülevaade akritarhide levikust kambriumi ja ordoviitsiumi piirikihtides Suhkrumäe paljandis, milles on selgitatud ka konodontide tsonaalsus.

Uuritud läbilōikes eraldub selgesti kaks akritarhide kompleksi. Neist a!umine iseloomustab Ulgase kihistut, teine aga Kallavere kihistu Maardu kihistikku. Olemine akritarhide kompleks ei ole kogu ulatuses ühtlane: nii ilmuvad Maardu kihistiku ülemises, argilliidivahekihi proovis Cordylodus lindstromi sisaldavate liivakivide all Lunulidia lunula, Acanthodiacrodium echinatum ja A. striatum, mis lamava C. proavus'e tsooni proovides puuduvad.

\section{N. VOLKOVA, Kaisa MENS}

\section{DISTRIBUTION OF ACRITARCHS IN THE CAMBRIAN-ORDOVICIAN BOUNDARY BEDS OF THE SUHKRUMÄGI SECTION (NORTH-ESTONIA)}

In the studied section the Cambrian-Ordovician boundary beds are represented by the Upper Cambrian Olgase Formation and the Lower Ordovician Kallavere Formation. Both the formations consist mostly of quartzose sand-and siltstones of variable grain size with thin lenticular interbeds of compact clay and kerogenous argillites (see the Figure showing also the location of samples with acritarchs and conodonts). Sand- and siltstones of this section have been dated recently by means of conodonts. This enables us to follow the range of acritarch assemblages in relation to conodont zonation. 
Two acritarch assemblages have been established in argillaceous rocks of the boundary beds (the Table). The lower one is restricted to the Olgase Formation, the upper one comes from the Maardu Member of the Kallavere Formation. The considerable change in acritarch composition between the Ulgase and Kallavere Formations coincides with a break in sedimentation.

The Ulgase Formation yielding Leiofusa stoumonensis Vang. and Veryhachium dumontii Vang. together with Timofeevia phosphoritica Vang., Vulcanisphaera turbata Martin, etc. belongs to the lowermost Upper Cambrian. The acritarch assemblage of the Maardu Member (the Table) according to F. Martin (1982), S. M. Rasul (1979) et al., indicates the Tremadocian age but is not homogeneous to its full extent. So Lunulidia iunula, Acanthodiacrodium echinatum and A. striatum make their appearance in the interbed of kerogenous argillite just below the first occurrence of Cordylodus intermedium, $C$. lindstromi and $C$. prion. These species of acritarchs are possibly characteristic of the $C$. lindstromi Zone but this problem needs further detailed investigation. 